\title{
The Multidisciplinary Management of Acute Complicated Diverticulitis
}

\author{
Daniël P.V. Lambrichts ${ }^{a, b} \quad$ Arianna Birindelli $^{c-e} \quad$ Valeria Tonini $^{d}$ \\ Roberto Cirocchi $^{f}$ Maurizio Cervellera ${ }^{d}$ Johan F. Lange ${ }^{a, g, h}$ \\ Willem A. Bemelman ${ }^{b}$ Salomone Di Saverioc, ${ }^{c}$
}

${ }^{a}$ Erasmus University Medical Center Rotterdam, Department of Surgery, Rotterdam, The Netherlands; ${ }^{b}$ Academic Medical Center Amsterdam, Department of Surgery, Amsterdam, The Netherlands; ' ${ }^{\mathrm{E}}$ Emergency and Trauma

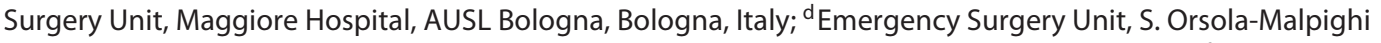
University Hospital, Bologna, Italy; ${ }^{\mathrm{e}}$ Queen Elizabeth University Hospital NHS, Birmingham, UK; ${ }^{\mathrm{f}}$ University of Perugia, Perugia, Italy; ${ }^{9}$ Jsselland Ziekenhuis, Department of Surgery, Capelle aan den IJssel, The Netherlands; ${ }^{h}$ Havenziekenhuis, Department of Surgery, Rotterdam, The Netherlands; ' Cambridge Colorectal Unit, Cambridge University Hospitals NHS Foundation Trust, Addenbrooke's Hospital, Cambridge, UK

\section{Keywords}

Complicated diverticulitis · Laparoscopic lavage $\cdot$ Minimally invasive surgery · Multidisciplinary management ·

Percutaneous drainage

\begin{abstract}
Background: Acute complicated diverticulitis (ACD) is an important and increasing issue in Western countries that leads to a significant impact and burden for patients, but also for the society due to its effects on hospital costs. In recent years, essential progression has been made regarding the research and implementation of novel or improved treatment strategies for the various disease entities of ACD. Much debated topics in the multidisciplinary approach of patients with ACD, such as the choice for nonoperative treatment options, the role of percutaneous drainage for diverticular abscesses, the role of laparoscopic lavage for perforated diverticulitis with purulent peritonitis, and the role of sigmoidectomy with primary anastomosis for patients with perforated diverticulitis, require clinicians to at-
\end{abstract}

tentively follow and participate in these discussions. Summary: The aim of this review article is to provide clinicians with a structured overview of the recent literature on the multidisciplinary management of complicated diverticulitis by a panel of experts on the topic. By performing an extensive literature search in the online medical databases MEDLINE (Ovid) and Embase, insights into nonoperative treatment, percutaneous drainage, minimally invasive and open surgical treatment of $A C D$ are provided. Furthermore, a comprehensive algorithm for the treatment of ACD has been developed. Key Messages: Accurate patient evaluation and selection based on patient and disease characteristics is of paramount importance to determine the appropriate treatment strategy for patients with complicated diverticulitis. The presence of an experienced surgeon with advanced skills in laparoscopic emergency colorectal surgery is crucial for the treatment of patients with perforated diverticulitis in order to properly evaluate, select and treat patients suitable for nonoperative or operative treatment with an open or laparoscopic approach.

(c) 2018 S. Karger AG, Basel

\section{KARGER}

(C) 2018 S. Karger AG, Basel 


\section{Introduction}

\section{Epidemiology}

Diverticulosis coli is a common condition in Western countries with prevalence rates of $5 \%$ by the age of 40 years up to $65 \%$ when 85 years or older [1]. An estimated $15-20 \%$ of individuals with diverticulosis coli will develop acute complicated diverticulitis (ACD) in their lifetime [2]. The age group of patients with ACD below 50 years of age consists predominantly of men, whereas women seem to be the majority in the group between 50 and 70 years [1]. In recent years, a considerable increase in both uncomplicated and complicated diverticulitis rates have been found, as well as a significant rise in hospital admissions. This has led to a significant increase in associated hospital expenditure of up to 2.4 billion dollars of direct costs annually in the United States [3,4].

\section{Terminology}

The terminology used in the literature regarding diverticulosis coli and diverticular disease is heterogeneous, so uniformity is required in order to correctly interpret and compare results between studies. The general term "diverticular disease" indicates that diverticulosis has risen to the level of illness [4]. In the majority of national and international guidelines, acute diverticulitis is further divided into complicated and uncomplicated disease [5]. Uncomplicated acute diverticulitis is defined as localized diverticular inflammation without any phlegmon, abscess, perforation, or fistula, whereas acute complicated diverticulitis (ACD) is defined as acute inflamed diverticula giving rise to phlegmon, abscess, fistula, or perforation [6]. Moreover, recurrent episodes of ACD can lead to late complications such as stenosis or fistula [5].

\section{Classifications of ACD}

After Hinchey et al. [7] presented their classification for ACD, various modifications and novel classifications have been proposed to grade the different entities of diverticular disease and ACD in particular (Table 1). The Hansen/Stock clinical classification comprises diverticulosis, as well as uncomplicated and complicated diverticulitis [8]. Likewise, Köhler et al. [9] introduced a classification including uncomplicated and recurrent ACD. Both these classifications were based on the clinical severity of the disease, whereas the Hinchey classification was based on operative findings. However, as a result of the increasing role of computed tomography (CT) as a diagnostic tool, subcategories could be defined and modified Hinchey classifications were introduced, as well as CT-based clas-

The Multidisciplinary Management of Acute Complicated Diverticulitis sifications, as those by Kaiser et al. [10] and Ambrosetti et al. [11]. Modified Hinchey classifications have been introduced by Sher et al. [12] and Wasvary et al. [13], of which the latter is the most widely adopted, focusing not only on perforated disease, but also on mild clinical disease. The number of classifications and the fact that they are based on different clinical, radiological or operative findings has led to discordance in the literature. However, as Klarenbeek et al. [14] stated, a proper classification is necessary to improve communication between doctors, support clinical decision-making, and provide help in the prediction of outcomes. Subsequently, they designed a comprehensive grading system that combined existing classifications and differentiates three stages of diverticular disease: uncomplicated, chronic complicated, and acute complicated. For each of these stages, clinical characteristics, radiological findings, and treatment modalities are given [14]. More recently, Sartelli et al. [15] have proposed a CT-based classification, with suggested management options, to drive decision-making in nonoperative and operative treatment of ACD. Nevertheless, currently, the modified Hinchey classification (Fig. 1) remains the most widely used classification and is used in several guidelines, and will be further referred to in this review $[5,13]$.

\section{Diagnosis}

In the clinical workup of ACD it is of paramount importance to diagnose and differentiate patients timely and correctly in order to initiate appropriate management. Moreover, accurate staging of the disease has become increasingly important, since treatment approaches have become less aggressive and more tailored to the stage of diverticulitis [16]. The clinical diagnosis of ACD seems to be correct in $43-68 \%$ of patients, when only based on symptoms, physical examination and laboratory results [1]. External validation of a clinical decision rule has shown that isolated tenderness in the left lower quadrant, C-reactive protein level of $>50 \mathrm{mg} / \mathrm{L}$, and absence of vomiting might have predictive value in patients with suspected acute diverticulitis. However, it must be acknowledged that these criteria only identified up to $24 \%$ of patients and, therefore, clinical assessment still remains insufficiently precise [17]. It is suggested that in these patients imaging might be omitted, but in general, the clinical diagnosis of ACD is not sufficiently accurate and all guidelines recommend radiological evidence to support clinical diagnosis $[1,5]$. Diagnostic techniques that have been assessed are double-contrast barium enemas, magnetic resonance imaging (MRI), colonoscopy, ultrasound (US), and CT scan. However, double-contrast barium enema is 
Table 1. Overview of classifications for diverticular disease

\begin{tabular}{|c|c|c|c|c|c|c|c|}
\hline \multicolumn{5}{|l|}{ Clinical findings } & \multicolumn{3}{|l|}{ CT findings } \\
\hline $\begin{array}{l}\text { Hinchey } \\
\text { et al. [7] }\end{array}$ & $\begin{array}{l}\text { Sher } \\
\text { et al. [12] }\end{array}$ & $\begin{array}{l}\text { Wasvary } \\
\text { et al. [13] }\end{array}$ & $\begin{array}{l}\text { Hansen } \\
\text { et al. [8] }\end{array}$ & $\begin{array}{l}\text { Köhler } \\
\text { et al. [9] }\end{array}$ & $\begin{array}{l}\text { Kaiser } \\
\text { et al. [10] }\end{array}$ & $\begin{array}{l}\text { Ambrosetti } \\
\text { et al. [11] }\end{array}$ & $\begin{array}{l}\text { Sartelli } \\
\text { et al. [15] }\end{array}$ \\
\hline \multicolumn{8}{|c|}{ Uncomplicated disease } \\
\hline \multirow[t]{2}{*}{-} & \multirow[t]{2}{*}{-} & - & 0 . Diverticulosis & \multirow{2}{*}{$\begin{array}{l}\text { Symptomatic } \\
\text { uncomplicated }\end{array}$} & \multirow[t]{2}{*}{ - } & \multirow[t]{2}{*}{-} & \multirow{2}{*}{$\begin{array}{l}\text { Diverticula, } \\
\text { thickening of the } \\
\text { wall, increased } \\
\text { density of the } \\
\text { pericolic fat }\end{array}$} \\
\hline & & $\begin{array}{l}\text { 0. Mild clinical } \\
\text { diverticulitis }\end{array}$ & $\begin{array}{l}\text { I. Acute } \\
\text { uncomplicated } \\
\text { diverticulitis }\end{array}$ & & & & \\
\hline \multicolumn{8}{|c|}{ Complicated disease } \\
\hline \multirow[t]{2}{*}{$\begin{array}{l}\text { I. Pericolic } \\
\text { abscess or } \\
\text { phlegmon }\end{array}$} & I. Pericolic abscess & $\begin{array}{l}\text { Ia. Confined } \\
\text { pericolic } \\
\text { inflammation or } \\
\text { phlegmon } \\
\text { Ib. Pericolic or } \\
\text { mesocolic abscess }\end{array}$ & $\begin{array}{l}\text { II. Acute } \\
\text { complicated } \\
\text { diverticulitis } \\
\text { IIa. Phlegmon, } \\
\text { peridiverticulitis } \\
\text { IIb. Abscess, } \\
\text { sealed perforation } \\
\text { IIc. Free } \\
\text { perforation }\end{array}$ & $\begin{array}{l}\text { Complicated } \\
\text { disease: } \\
\text { - Hemorrhage } \\
\text { - Abscess } \\
\text { - Phlegmon } \\
\text { - Fistula } \\
\text { - Stricture } \\
\text { - Perforation } \\
\text { - Purulent and } \\
\text { fecal peritonitis } \\
\text { - Small bowel } \\
\text { obstruction due to } \\
\text { postinflammatory }\end{array}$ & $\begin{array}{l}0 \text {. Diverticuli }+/- \\
\text { colonic wall } \\
\text { thickening }\end{array}$ & $\begin{array}{l}\text { Moderate } \\
\text { diverticulitis: } \\
\text { - Localized } \\
\text { sigmoid wall } \\
\text { thickening } \\
(<5 \mathrm{~mm}) \\
\text { - Pericolic fat } \\
\text { stranding }\end{array}$ & $\begin{array}{l}\text { Ia. Pericolic air } \\
\text { bubbles or little } \\
\text { pericolic fluid } \\
\text { without abscess } \\
\text { Ib. Abscess } \leq 4 \mathrm{~cm}\end{array}$ \\
\hline & \multirow{2}{*}{$\begin{array}{l}\text { IIa. Distant abscess } \\
\text { amenable to } \\
\text { percutaneous } \\
\text { drainage } \\
\text { IIb. Complex } \\
\text { abscess associated } \\
\text { with fistula }\end{array}$} & & & adhesions & \multirow{2}{*}{$\begin{array}{l}\text { Colonic wall } \\
\text { thickening with } \\
\text { pericolic soft tissue } \\
\text { changes: } \\
\text { Ia. Changes + } \\
\text { pericolic or mesocolic } \\
\text { abscess } \\
\text { Ib. Changes + distant } \\
\text { abscess (generally } \\
\text { deep in the pelvis or } \\
\text { interloop regions) }\end{array}$} & & $\begin{array}{l}\text { IIa. Abscess } \\
>4 \mathrm{~cm} \\
\text { IIb. Distant air ( }>5 \\
\mathrm{~cm} \text { from inflamed } \\
\text { bowel segment) }\end{array}$ \\
\hline $\begin{array}{l}\text { II. Pelvic, intra- } \\
\text { abdominal or } \\
\text { retroperitoneal } \\
\text { abscess }\end{array}$ & & $\begin{array}{l}\text { II. Pelvic, distant } \\
\text { intra-abdominal } \\
\text { or retroperitoneal } \\
\text { abscess }\end{array}$ & & & & $\begin{array}{l}\text { Severe } \\
\text { diverticulitis: } \\
\text { - Abscess } \\
\text { - Extraluminal air } \\
\text { - Extraluminal } \\
\text { contrast }\end{array}$ & $\begin{array}{l}\text { III. Diffuse fluid } \\
\text { without distant free } \\
\text { air (no hole in } \\
\text { colon) }\end{array}$ \\
\hline $\begin{array}{l}\text { III. Generalized } \\
\text { purulent } \\
\text { peritonitis }\end{array}$ & $\begin{array}{l}\text { III. Generalized } \\
\text { purulent peritonitis }\end{array}$ & $\begin{array}{l}\text { III. Generalized } \\
\text { purulent } \\
\text { peritonitis }\end{array}$ & & & $\begin{array}{l}\text { III. Free gas } \\
\text { associated with } \\
\text { localized or } \\
\text { generalized ascites } \\
\text { and possible } \\
\text { peritoneal wall } \\
\text { thickening }\end{array}$ & & $\begin{array}{l}\text { IV. Diffuse fluid } \\
\text { with distant free air } \\
\text { (persistent hole in } \\
\text { colon) }\end{array}$ \\
\hline $\begin{array}{l}\text { IV. Generalized } \\
\text { fecal peritonitis }\end{array}$ & $\begin{array}{l}\text { IV. Fecal } \\
\text { peritonitis }\end{array}$ & $\begin{array}{l}\text { IV. Generalized } \\
\text { fecal peritonitis }\end{array}$ & & & $\begin{array}{l}\text { IV. Same findings as } \\
\text { III }\end{array}$ & & \\
\hline \multicolumn{8}{|l|}{ Recurrent disease } \\
\hline- & & - & $\begin{array}{l}\text { III. Chronic } \\
\text { recurrent } \\
\text { diverticulitis }\end{array}$ & $\begin{array}{l}\text { Recurrent } \\
\text { symptomatic } \\
\text { disease }\end{array}$ & - & - & \\
\hline
\end{tabular}

contraindicated in the setting of suspected ACD, due to its low accuracy, high radiation exposure and low patient acceptability [18]. MRI has the advantage that contrast is not needed and does not expose the patient to ionizing radiation, but sufficient evidence and accuracy data are still lacking [19]. Furthermore, in many hospitals, availability of MRI in the emergency department is limited [18]. Colonoscopy is not recommended in the acute phase because of potential difficulties, such as incomplete bowel preparation, bowel stenosis, and the risk of perforation and bleeding $[18,20]$. US and CT are comparable in di- agnosing diverticulitis and superior to other modalities, with a sensitivity of 92 versus $94 \%$ and a specificity of 90 versus $99 \%$, respectively $[19,21]$. Nowadays, CT is the established method of choice when compared to US and most guidelines agree on the high accuracy and other advantages of CT [5, 22]. Andeweg et al. [19] published a step-up approach in which CT is performed after an inconclusive or negative graded compression US. Nevertheless, CT is recommended for severe peritonitis, since it is superior to US in providing an alternative diagnosis and detecting complicated disease $[5,16]$. 

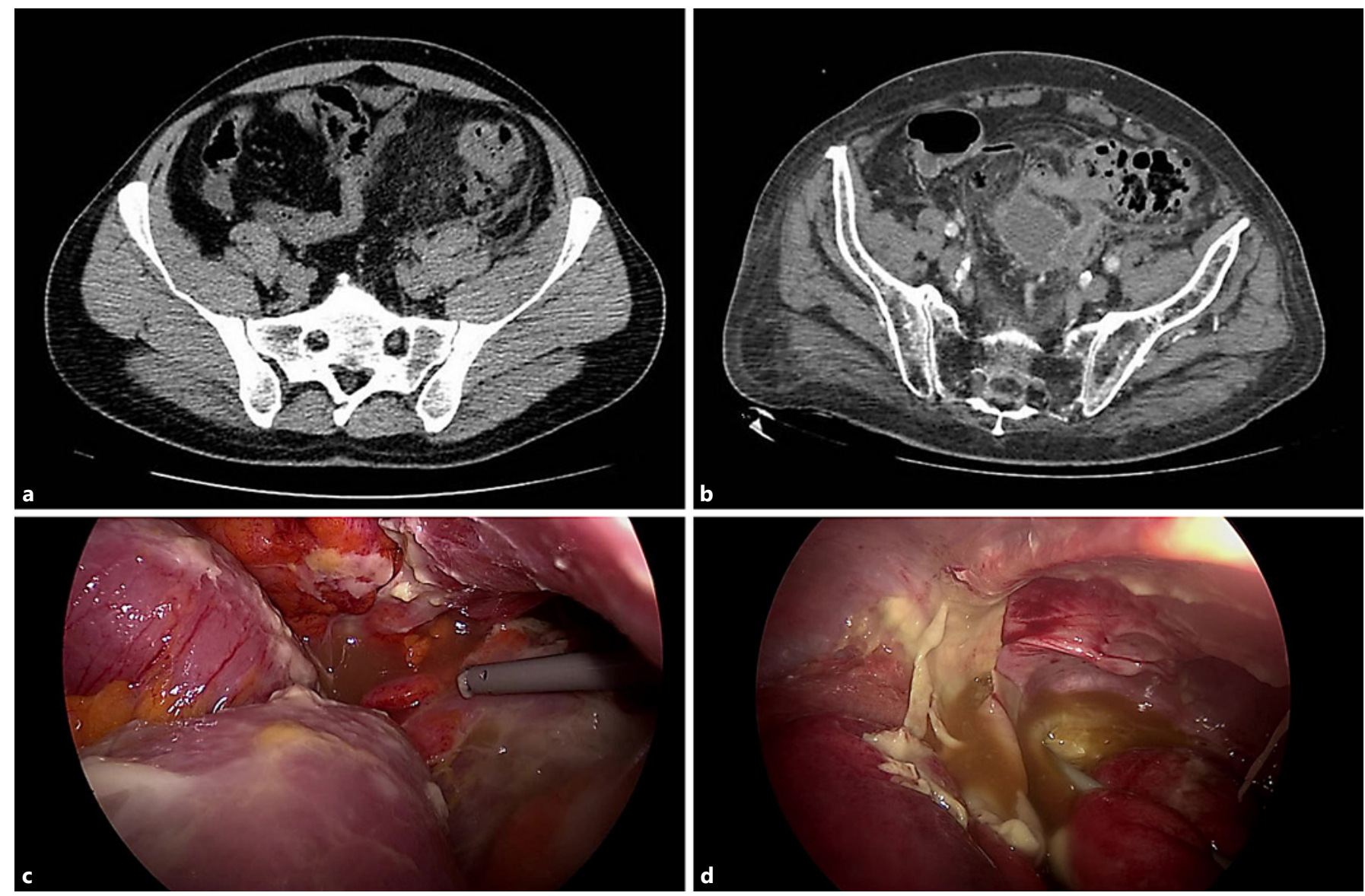

Fig. 1. Radiological and clinical images of the modified Hinchey classification. Hinchey Ib: CT image of pericolic abscess (a); Hinchey II: CT image of pelvic abscess (b); Hinchey III: intraoperative image of purulent peritonitis (c); Hinchey IV: intraoperative image of fecal peritonitis (d). Pictures provided by Dr. Salomone Di Saverio, MD, FACS, FRCS; patients gave permission to publish.

\section{Nonoperative Treatment}

In past decades, ACD management has moved towards a more nonoperative approach, by virtue of significant progression in critical care medicine, interventional radiological techniques, antibiotic treatment, parenteral nutrition, and diagnostic accuracy of CT [23]. Results of the DIABOLO trial by Daniels et al. [24] indicate that observational treatment without antibiotics did not prolong recovery and can be considered appropriate in Hinchey Ia and Ib patients. Moreover, Stam et al. [25] concluded that an unrestricted diet is safe in this patient population. Nowadays, the goal of surgical care for ACD is to convert an emergent surgical situation into an elective situation, by means of aggressive, supportive medical care $[23,26]$. Despite this important change in treatment strategy, literature on this topic is scarce, especially concerning more complex cases of ACD. Consequently, op-

The Multidisciplinary Management of Acute Complicated Diverticulitis timal treatment strategies remain controversial, notably in patients presenting with extraluminal air [27]. A considerable overall success rate of $91 \%$ for a nonoperative approach in patients with extraluminal air was reported by Dharmajaran et al. [23], who managed patients in a monitored setting, with intravenous (IV) fluids, broadspectrum IV antibiotics, and bowel rest, according to local protocol. If possible, percutaneous drainage (PCD) was advised in patients with an abscess larger than $4 \mathrm{~cm}$, indicating the importance of a multidisciplinary management with involvement of interventional radiologists. Sallinen et al. [27] reported a $62 \%$ success rate in patients with distant intraperitoneal air, although this rate increased to $86 \%$ when patients with abundant distant intraperitoneal air or fluid in the recto-vesical or recto-uterine pouch were excluded. In the World Society of Emergency Surgery (WSES) guidelines [28] it is stated that 
patients with CT findings of pericolic air or small fluid collection should be managed by antimicrobial therapy. Furthermore, it is articulated that nonoperative treatment might be an option in selected patients with distant air, but without diffuse fluid on CT. However, clearly, surgery is still indicated in case of failure of this approach. Initial choice of antibiotic regimen should be empirical and therefore partly depends on presumable pathogens involved, as well as local resistance profiles and other risk factors for resistance patterns [29]. Additional CT imaging is advised in patients with persistent signs of intraabdominal infection after 4-6 days, or in case of recurrent evidence of infection [15]. Although the reported results seem to indicate that nonoperative management is a viable option, even in patients with extraluminal air, a careful case-by-case decision should still be made, with attention to the patient's clinical state [30,31]. Evidently, nonoperative management is contraindicated in case of hemodynamic instability, generalized peritonitis, diffuse free air and fluid on CT, immunosuppression, or comorbidities that hinder the resolution of sepsis [23].

\section{Percutaneous Drainage}

An important group of patients with ACD that can initially be treated nonsurgically are patients with diverticular abscess formation (Hinchey IIa and IIb). This peri- or paracolic abscess formation occurs in $15-40 \%$ of ACD cases and is caused by bacteria and inflammatory cells spreading into the mesocolon and peritoneal cavity [32]. Treatment choice in the acute setting depends on clinical presentation, size, and location of the abscess, as well as the amenability for PCD [32]. At present, no definite consensus has been reached on the optimal approach for this patient group, due to the lack of high-quality research [1]. Definitions of a large abscess vary from 2 to $5 \mathrm{~cm}$ throughout the literature, but the cutoff value of $>4-5 \mathrm{~cm}$ is generally used in publications and guidelines $[1,5,28,32]$. However, as supported by several international guidelines, small mesocolic abscesses can be treated with antibiotics alone, whereas larger mesocolic or pelvic abscesses require PCD [5]. In case of small abscesses $(<4-5 \mathrm{~cm})$, bowel rest, pain control and IV antibiotics are advised. In the absence of clinical trials comparing antibiotic regimens, recommendations on specific agents or treatment duration cannot be made [33]. Nevertheless, broad-spectrum, IV antibiotics, covering anaerobic and gram-negative bacteria, are considered as essential component of successful nonoperative treatment $[33,34]$. In the choice of imaging modality, US-guided drainage has the benefit of easy handling, low costs and avoidance of ionizing radiation. However, despite these benefits, the US-guided method might be predominantly convenient in superficial abscesses, partly because the air acoustic barrier of bowel loops can limit the abdominal approach [35]. CT-guided PCD is considered to be the preferred and the most effective method for the detection and interventional guidance of abscess drainage in the abdomen and pelvis because of the anatomic detail and localization related to nearby vital structures $[35,36]$. Several access routes for interventional radiological drainage exist such as the transabdominal approach (anterior or lateral) and transgluteal approach. The latter approach can be considered as an option for deep pelvic abscesses and requires CT guidance $[35,36]$. Furthermore, endocavitary (e.g., transrectal) approaches might be suitable for more complex, deep pelvic collections [35, 36]. Endoscopic transluminal abscess drainage has been proposed as a treatment option for diverticular abscesses; however, no strong evidence exists on this topic [37-40].

Both the direct trocar technique and the Seldinger technique can be used during the procedure, of which the trocar technique seems faster and better suited for large fluid collections, whereas the Seldinger technique is more time-consuming and suitable for complex pelvic collections $[35,36]$. The size of the catheter depends on the viscosity of the fluid and should not be too small to avoid kinking and clogging. Moreover, daily flushing of the catheter is recommended to maintain effective drainage $[35,36]$. The timing of catheter removal can be based on clinical and imaging criteria [35]. If resolution of the abscess is not reached and the patient has no clinical improvement, repeated CT and further drainage or catheter repositioning might be indicated, and eventually necessitate surgery [28, 35, 41]. Laparoscopic drainage has a limited role in the treatment of diverticular abscesses, but may be considered in case of a large abscess that is not amenable for PCD [42].

In their systematic review, Gregersen et al. [32] found that the nonoperative treatment failure rate, regardless of treatment choice, was $19-21 \%$ for both PCD and antibiotic treatment, with failure defined as emergency surgery, readmission or mortality within 30 days from initial treatment, residual abscess, or persistent symptoms. However, these results need to be carefully interpreted, because treatment groups may primarily reflect disease severity (indication/selection bias), since antibiotics were mainly used for smaller and primarily Hinchey Ib abscesses, and PCD for larger, Hinchey II abscesses. Several reasons for treatment failure of PCD have been identified, such as a multiloculated or pelvic abscess occurrence, or patients 
with significant comorbidities [32, 41]. Jalouta et al. [43] found a $77 \%$ recurrence-free survival after nonoperative treatment. Overall, a pooled recurrence rate of $25.5 \%$ is observed in the nonoperative treatment group, consisting of patients treated with antibiotics and/or PCD, whereas PCD and antibiotics alone have a pooled average recurrence rate of 15.9 and $22.2 \%$, respectively [32]. However, the overall recurrence can get as high as $68 \%$, especially in risk groups of patients with abscesses larger than $>5 \mathrm{~cm}$ or at pelvic or distant locations [32, 34]. Moreover, Gregersen et al. [32] found a weighted average of $4.8 \%$ (median $1.3 \%$, range $0-18.2 \%$ ) of acute or urgent surgery due to recurrence following successful nonoperative treatment.

No clear consensus exists on follow-up after the nonoperative treatment of diverticular abscesses, although the WSES guideline advises early colonoscopic evaluation (4-6 weeks) [28]. More importantly, the role and necessity of elective surgery is still debated. Although no strong evidence exists, from their systematic review, Lamb and Kaiser [34] have concluded that abscess formation is associated with a high probability of resectional surgery at follow-up, while nonoperative management may evidently result in recurrent diverticular disease. Therefore, the choice for elective surgery should be made on a case-by-case basis, until future research clarifies how to select patients for whom elective surgery might be indicated $[5,34]$.

\section{Operative Treatment}

\section{Minimally Invasive Operative Treatment}

Although the open approach is still the most common in operative treatment of $\mathrm{ACD}$, encouraging data on the feasibility and advantages of laparoscopic treatment have been published and the minimally invasive approach in the management of ACD has been included in the EAES, Dutch, and WSES guidelines [5, 28, 44].

Patients needing operative treatment of ACD are commonly critical and their clinical status might be severely impaired by sepsis. In these patients, laparotomy often leads to high morbidity rates (e.g., wound infection, pneumonia, renal failure, adhesions, and incisional hernias). Therefore, especially in these acute patients, the minimally invasive surgical treatment might significantly decrease postoperative complication rates and allow a faster recovery, as compared to the open approach. However, to proceed to a laparoscopic treatment of ACD, it is of paramount importance that the patient is hemody-

The Multidisciplinary Management of Acute Complicated Diverticulitis namically stable and has no absolute contraindications to pneumoperitoneum. Either severely inflamed tissues in perforated ACD or severe bowel distention in obstructing ACD make the surgical procedure technically demanding and the presence of an acute care surgeon with advanced laparoscopic colorectal skills is recommended.

According to the patient's status, available surgical expertise and the extent and severity of the underlying disease, the surgical treatment of ACD can be either nonresectional or resectional.

\section{Laparoscopic Nonresectional Treatment}

Laparoscopic lavage (LL) has first been described in 1996 as a minimally invasive technique to avoid resection in perforated diverticulitis with purulent peritonitis $[45$, 46]. Since then, the technique has not gained a wide acceptance and, up to date, three randomized controlled trials (RCTs) comparing LL to sigmoidectomy have been published [47-49]. Interestingly, their conclusions did not agree and the strong debate raised from these conflicting results led 7 meta-analyses to be published over the last 2 years [50-56]. Some authors claimed selection biases in the RCTs [57] or methodological flaws in the meta-analyses, since opposite conclusions on the 30-day and 90-day reoperation risk were reported in the metaanalyses [58]. Despite its increased incidence of postoperative abscesses and PCD, LL still appears to be faster and leading to a faster recovery. No indisputable differences in terms of postoperative short- and long-term mortality, morbidity and stoma presence at 12 months seem to be present [50-56]. LL might, however, be more cost-effective as compared to resection $[59,60]$.

The main factor related to failure or success of $L L$ is the grade of experience of the operator [61]. The intraoperative distinction between Hinchey III and IV is not always obvious and experience and technical skill are essential features for effective irrigation, drainage and, most importantly, reliably ruling out free perforation or perforated cancer [61]. An experienced surgeon is better able to distinguish between purulent and fecal peritonitis and is more likely to be able to identify the perforation, which mostly is on the mesenteric side of the sigmoid, surrounded by dense inflammatory tissue, and therefore not easily accessible or visible. Intraoperative endoscopy or insufflation of $\mathrm{CO}_{2}$ in the rectum might be helpful to discriminate between a sealed or open perforation. Furthermore, since purulent peritonitis is the consequence of transient peritoneal contamination, with a sealed perforation at the time of the operation, the main aim of LL might not be to control the source of infection, but to 
clean the peritoneal cavity, reduce microbial contamination and the consequent release of inflammatory factors, in order to improve sepsis treatment. In this view, the peritoneal washout must be as complete and careful as possible, including thorough cleaning of all four quadrants' recesses and placement of abdominal drains deep in the Douglas' and Morison's pouches. Inexperienced surgeons might be less competent to correctly perform these procedural steps, potentially leading to an increased rate of persistent sepsis or intra-abdominal collections. LL may represent a valuable option for the management of perforated diverticulitis with purulent peritonitis; however, the risk of failure, early reintervention, perforated carcinoma and diverticulitis recurrence need to be balanced against the risk of sigmoidectomy, and potential stoma formation and closure $[49,62]$. Therefore, correct patient evaluation, performed by an experienced surgeon, with advanced skills in laparoscopic emergency colorectal surgery, is crucial for the selection and treatment of stable, young and fit patients, without an overt perforation.

\section{Laparoscopic Resectional Treatment}

The literature on emergency laparoscopic Hartmann's procedure (HP) or sigmoidectomy with primary anastomosis (PA) for ACD is still scant. Several small retrospective cohort studies and case series have been published, but no RCTs comparing the laparoscopic and open approach in the acute setting exist [63], mostly because of concerns about the clinical characteristics of ACD that, potentially, negatively affects outcomes of the laparoscopic approach. In the acute setting, the distended bowel, inflammatory dense adhesions, and the contamination of the abdominal cavity caused by perforated ACD often raise concerns on the safety and feasibility of the approach. Moreover, the severely inflamed tissues make the procedure remarkably more challenging if compared to the elective sigmoid colectomy (Fig. 2), with loss of anatomical planes and consequent increased risk of bleeding and ureteric injuries. Because of these technical demands, it is therefore advisable to consider these procedures only in the presence of an experienced surgeon, who is highly skilled in emergency laparoscopic colorectal surgery.

Small retrospective series have demonstrated emergency laparoscopic sigmoidectomy in ACD to be safe and feasible, with significant advantages in terms of low conversion, reintervention, morbidity, and mortality rates, as well as faster recovery, and higher stoma reversal rates [64]. Although the published studies are limited by their small size, heterogeneity of participants and outcome
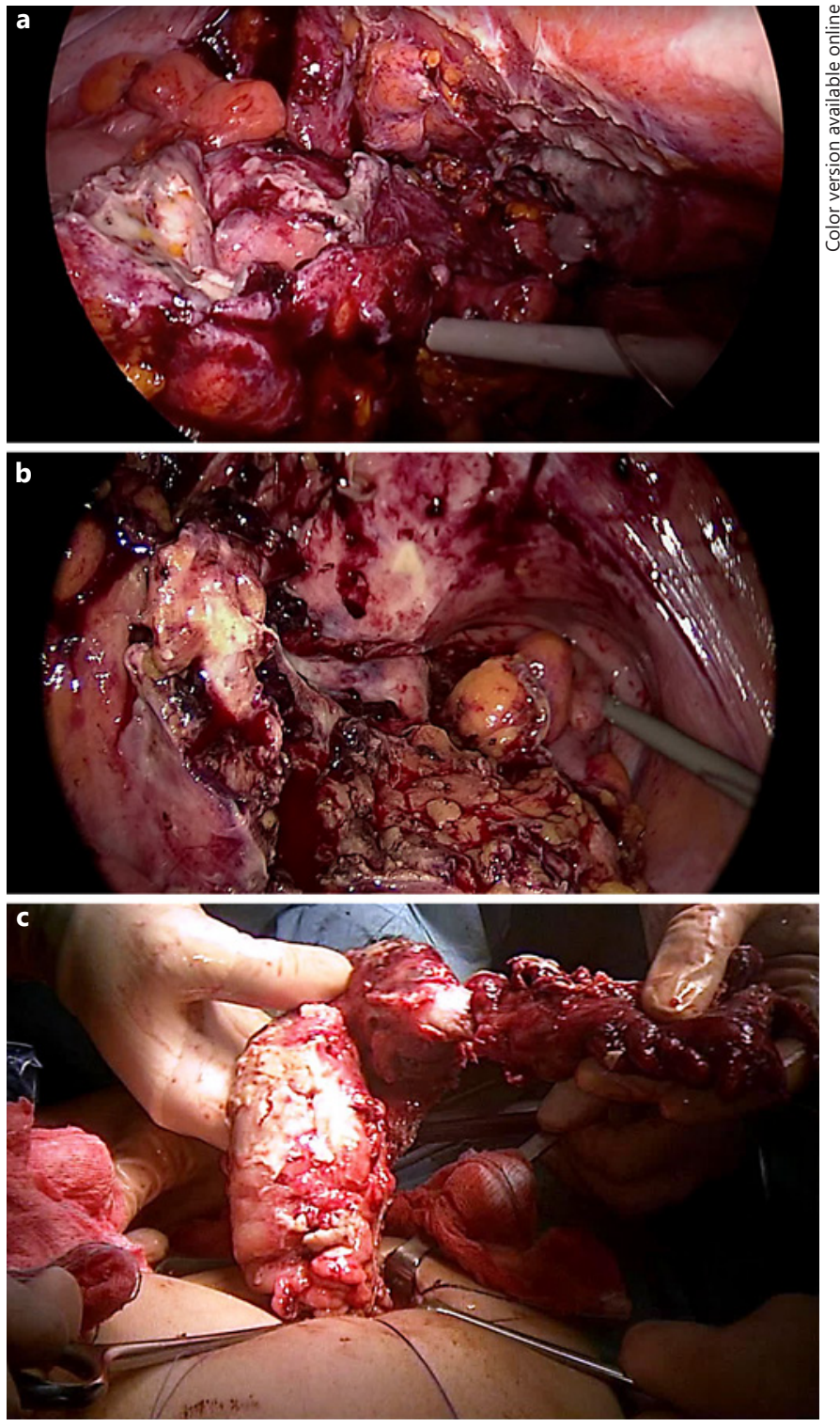

Fig. 2. Operative steps of laparoscopic HP for ACD. After the inflamed and thickened sigmoid mesocolon is dissected (a), the sigmoid colon is mobilized and the distal intracorporeal stapled resection is performed (b). The specimen is extracted through the colostomy site avoiding any laparotomy (c) and therefore reducing the risk of wound infection and incisional hernia. Operative pictures provided by Dr. Salomone Di Saverio, MD, FACS, FRCS; the patient gave permission to publish.

variables, obvious selection bias, and lack of open control group, it is still stated that the approach is feasible in selected patients and experienced hands [64], as was also concluded in a recent propensity score-matched analysis [65]. Furthermore, the benefit of laparoscopic HP might be a decrease in abdominal wall complications, such as 
incisional hernias [65]. Subsequently, this might lead to higher rates of stoma reversal in the follow-up of these patients.

In selected cases, it can be decided to perform a sigmoidectomy with PA, with or without defunctioning loop ileostomy, depending on the patient's age, comorbidities, and clinical condition. Furthermore, the intraoperative quality of colonic tissue and edges is of importance (e.g., not ischemic), and it is important that these can be joined without tension, making routine splenic flexure mobilization highly recommendable. The role of defunctioning loop ileostomy can be debated in emergency procedures since the colon has not been prepared, even though an intraoperative colonic anterograde enema through the appendicular orifice may be performed after the resection and PA have been performed. The largest reported series of emergency laparoscopic anterior resection and PA for complicated diverticular disease is the one by Titu et al. [66] including 50 cases, with an anastomotic leak rate of $8 \%$. The retrospective comparative cohort study by Letarte et al. [67] included 103 emergency colonic resections and primary anastomosis (37 laparoscopic vs. 66 open) for acute complicated diverticulitis, with no significant difference in the anastomotic leak rate. Overall, no mortality and significantly better postoperative outcomes were found in the laparoscopic group, in terms of less frequent prolonged ileus (12.8 vs. $32 \%)$, shorter time to oral intake (3 vs. 6 days) and shorter length of stay (5 vs. 8 days) [67]. Moreover, Vennix et al. [63] performed a systematic review of 4 case series and 1 cohort study, in which a total of 104 patients underwent emergency laparoscopic resection for perforated diverticulitis (84 Hartmann, 20 primary anastomoses). Mean operating time varied between 115 and $200 \mathrm{~min}$, conversion rate varied from 0 up to $19 \%$, mean hospital stay ranged between 6 and 16 days, surgical reintervention was necessary in 2 patients, no anastomotic leak was reported, and 3 patients died postoperatively. In highly selected and fit patients, the presence of fecal gross contamination, with peritonitis lasting less than 12-24 h, might not be an absolute contraindication to laparoscopic resection and PA, although data on this topic are limited [68]. Accordingly, the essential aspects of laparoscopic resectional treatment are accurate patient evaluation, selection and treatment by experienced laparoscopic colorectal surgeons.

Before embarking in challenging laparoscopic emergency colorectal procedures, expertise in acute care, emergency and colorectal surgery, as well as minimally invasive expertise (e.g., having completed a laparoscopic

The Multidisciplinary Management of Acute Complicated Diverticulitis fellowship) are required. In the absence of an experienced emergency colorectal laparoscopic surgeon, advanced laparoscopic procedures should not be performed and open procedures are advised outside centers of excellence $[61,69-72]$.

\section{Open Operative Treatment}

Although laparoscopic resectional treatment has gained increasing attention and promising results have been published, general peritonitis is often still regarded as a contraindication for the laparoscopic approach, especially when fecal. Moreover, concerns have been raised on the risk of damage to the vulnerable and distended small bowel, as well as the hypothetical risk of increased bacteremia and hypercapnia, caused by pneumoperitoneum $[63,65]$. Despite the fact that there is no strong evidence proving or disproving these concerns, laparotomy and HP are still the most commonly used procedures $[28,63]$. The role of sigmoid resection with PA versus HP has been discussed in several studies $[73,74]$. Potentially, PA, with or without construction of a temporary loop ileostomy, has the major benefit of avoiding an end colostomy, and the significant risks associated with Hartmann's reversal. In their systematic review, Constantinides et al. [73] found favorable results regarding mortality for PA as compared to HP; however, they correctly indicated the considerable risk of selection bias in the studies under review, due to their retrospective design. To reduce this bias, introduced by performing PA in more favorable subjects, prospective randomized studies were soon designed and conducted. As stated by the authors, from the prematurely terminated trial by Binda et al. [75], no conclusions could be drawn on treatment preference, although they included a total of 90 patients (15\% of calculated sample size) of which 15 patients (16.7\%) had Hinchey IV. Furthermore, Oberkofler et al. [76] published results favoring PA with diverting ileostomy over HP in a total of 62 patients ( $30 \mathrm{HP}$ vs. $32 \mathrm{PA}$ ). In the HP and PA group, respectively, postoperative outcomes were not significantly different (mortality 13 vs. $9 \%$ and morbidity 67 vs. $75 \%$ ). Nevertheless, the stoma reversal rate was higher and operating time, hospital stay, and in-hospital costs were significantly reduced in patients who underwent PA. Currently, results of the DIVA arm of the LADIES trial are awaited, in order to further elucidate this important and much discussed surgical topic [77]. Despite the absence of strong evidence, HP is advised for critically ill patients or patients with multiple comorbidities, whereas PA, with or without a diverting loop ileostomy, is considered safe or even preferable for 


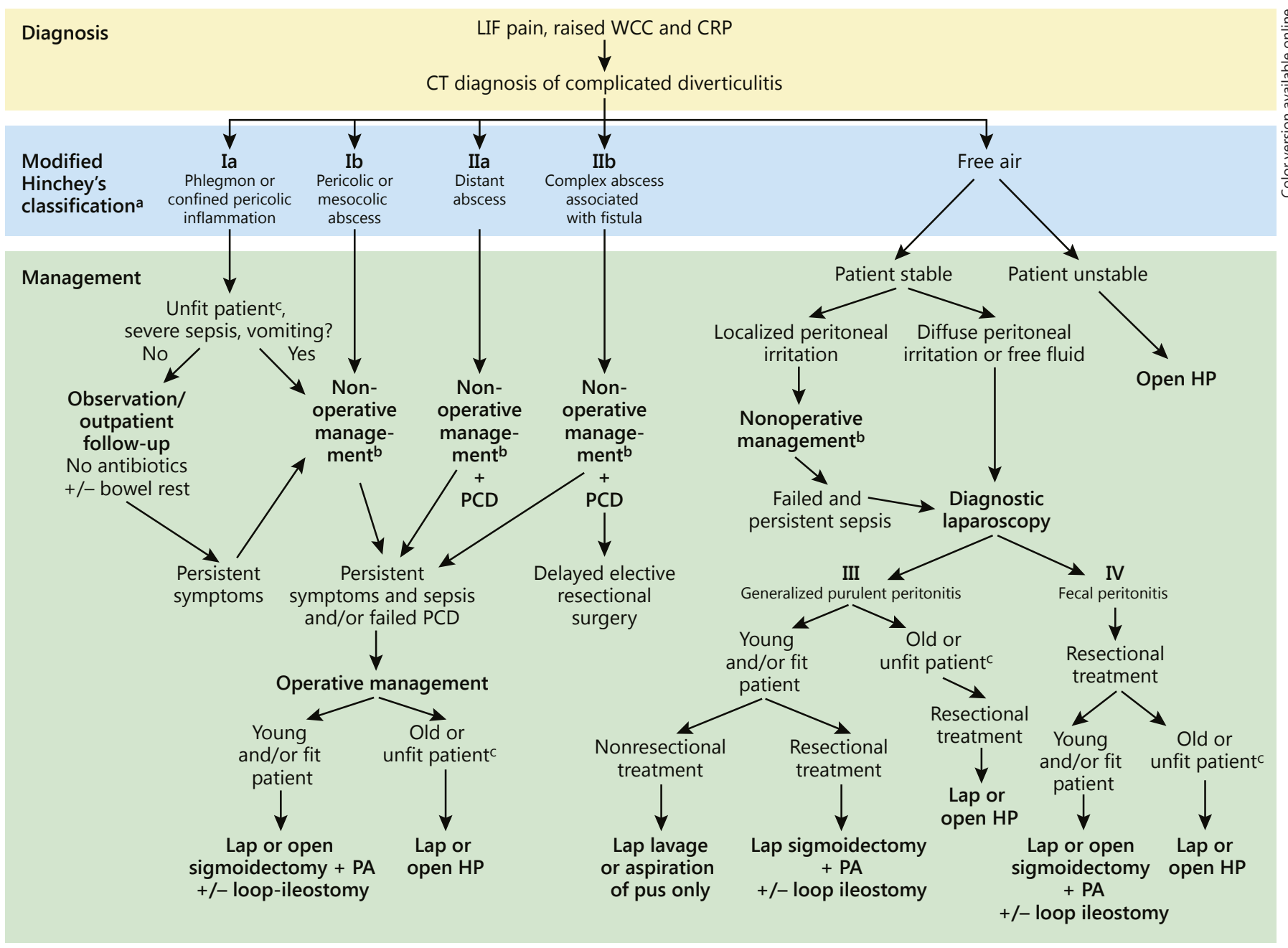

Fig. 3. Proposed algorithm for the multidisciplinary management of ACD. PCD, percutaneous drainage; HP, Hartmann's procedure; PA, primary anastomosis. ${ }^{a}$ According to Waswary et al. [13] and Sher et al. [12]. ${ }^{\mathrm{b}}$ Broadspectrum IV antibiotics and bowel rest. ${ }^{\mathrm{c}}$ Immunosuppressed, diabetes, chemotherapy, multiple comorbidities.

hemodynamically stable patients with Hinchey III and IV diverticulitis or after failed nonoperative treatment of ACD (Hinchey I-III) [1, 5, 28].

\section{Conclusions}

Diverticulitis is an important and increasing problem in Western countries, leading to an increase in hospital admissions and expenditure. Therefore, the use of uniform and comprehensive terminology and disease classification is necessary in order to improve diagnostics, subsequent treatment choices, and future research related to ACD. Contrast CT scan is the gold standard for the di- agnosis of ACD. Due to advances in critical care medicine and interventional radiological techniques nonoperative treatment strategies might be viable even in highly selected patients with extraluminal air. In case of abscess formation, size and location of abscess should, apart from patient characteristics, be taken into consideration before performing PCD. In selected cases and in the presence of an experienced emergency colorectal laparoscopic surgeon, minimally invasive operative management of ACD is feasible and has multiple advantages. Benefits and risks of LL should, evidently, be balanced with those of resectional treatment. HP (open or laparoscopic) is the most common resectional treatment in case of ACD with peritonitis, failed nonoperative management of $\mathrm{ACD}$ or acute 
large bowel obstruction resulting from diverticular disease. A benefit of laparoscopic HP might be a decrease in abdominal wall complications, such as incisional hernias, with a subsequently higher rate of stoma reversal. In case of resectional treatment (open or laparoscopic), a PA can be performed, with or without defunctioning loop ileostomy, depending on the patient's age, comorbidities and clinical condition, as well as intraoperative findings and quality of colonic tissue. According to the modified Hinchey classification of ACD, a comprehensive algorithm for the management of ACD has been developed (Fig. 3).
In conclusion, accurate patient evaluation based on clinical and disease characteristics is of paramount importance to determine the appropriate treatment strategy of ACD. Future research should aim to provide data supporting accurate case-by-case evaluation and decisionmaking in order to improve the various mentioned aspects of the multidisciplinary treatment of complicated diverticulitis.

\section{Disclosure Statement}

The authors declare that they have no conflicts of interest.

\section{References}

1 Andeweg CS, et al: Guidelines of diagnostics and treatment of acute left-sided colonic diverticulitis. Dig Surg 2013;30:278-292.

2 Delvaux M: Diverticular disease of the colon in Europe: epidemiology, impact on citizen health and prevention. Aliment Pharmacol Ther 2003;18(suppl 3):71-74.

3 Jena MD, et al: Epidemiologic analysis of diverticulitis. Clin Colon Rectal Surg 2016;29: 258-263.

4 Strate LL, et al: Diverticular disease as a chronic illness: evolving epidemiologic and clinical insights. Am J Gastroenterol 2012; 107:1486-1493.

5 Vennix S, et al: Systematic review of evidence and consensus on diverticulitis: an analysis of national and international guidelines. Colorectal Dis 2014;16:866-878.

6 Wilkins T, Embry K, George R: Diagnosis and management of acute diverticulitis. Am Fam Physician 2013;87:612-620.

7 Hinchey EJ, Schaal PG, Richards GK: Treatment of perforated diverticular disease of the colon. Adv Surg 1978;12:85-109.

8 Hansen O, Graupe F, Stock W: Prognostic factors in perforating diverticulitis of the large intestine. Chirurg 1998;69:443-449.

9 Köhler L, et al: Diagnosis and treatment of diverticular disease. Surg Endosc 1999;13:430436.

10 Kaiser AM, et al: The management of complicated diverticulitis and the role of computed tomography. Am J Gastroenterol 2005; 100: 910-917.

11 Ambrosetti P, Becker C, Terrier F: Colonic diverticulitis: impact of imaging on surgical management - a prospective study of 542 patients. Eur Radiol 2002;12:1145-1149.

12 Sher ME, et al: Laparoscopic surgery for diverticulitis. Surg Endosc 1997;11:264-267.

13 Wasvary H, et al: Same hospitalization resection for acute diverticulitis. Am Surg 1999;65: 632-635.
14 Klarenbeek BR, et al: Review of current classifications for diverticular disease and a translation into clinical practice. Int J Colorectal Dis 2012;27:207-214.

15 Sartelli M, et al: A proposal for a CT driven classification of left colon acute diverticulitis. World J Emerg Surg 2015;10:3.

16 Boermeester MA, et al: Contemporary review of risk-stratified management in acute uncomplicated and complicated diverticulitis. World J Surg 2016;40:2537-2545.

17 Kiewiet JJS, et al: External validation of two tools for the clinical diagnosis of acute diverticulitis without imaging. Dig Liver Dis 2014; 46:119-124.

18 Flor N, et al: The current role of radiologic and endoscopic imaging in the diagnosis and follow-up of colonic diverticular disease. Am J Roentgenol 2016;207:15-24.

19 Andeweg CS, et al: Toward an evidence-based step-up approach in diagnosing diverticulitis. Scand J Gastroenterol 2014;49:775-784.

20 Bugiantella W, et al: Left colon acute diverticulitis: an update on diagnosis, treatment and prevention. Int J Surg 2015;13:157-164.

21 Laméris W, et al: Graded compression ultrasonography and computed tomography in acute colonic diverticulitis: meta-analysis of test accuracy. Eur Radiol 2008;18:2498.

22 Böhm SK: Diagnostik und Klassifikation der Divertikelkrankheit. Visc Med 2012;28:171181.

23 Dharmarajan S, et al: The efficacy of nonoperative management of acute complicated diverticulitis. Dis Colon Rectum 2011;54:663671.

24 Daniels L, et al: Randomized clinical trial of observational versus antibiotic treatment for a first episode of CT-proven uncomplicated acute diverticulitis. Br J Surg 2017; 104:52-61.

25 Stam MA, et al: An unrestricted diet for uncomplicated diverticulitis is safe: results of a prospective diverticulitis diet study. Colorectal Dis 2017;19:372-377.
26 Shaikh S, Krukowski ZH: Outcome of a conservative policy for managing acute sigmoid diverticulitis. Br J Surg 2007;94:876-879.

27 Sallinen VJ, Mentula PJ, Leppaniemi AK: Nonoperative management of perforated diverticulitis with extraluminal air is safe and effective in selected patients. Dis Colon Rectum 2014;57:875-881.

28 Sartelli M, et al: WSES Guidelines for the management of acute left sided colonic diverticulitis in the emergency setting. World J Emerg Surg 2016;11:37.

29 Sartelli M, et al: 2013 WSES guidelines for management of intra-abdominal infections. World J Emerg Surg 2013;8:3.

30 Kim BC: Nonoperative management of acute complicated diverticulitis. Ann Coloproctol 2014;30:206.

-31 Costi R, et al: Challenging a classic myth: pneumoperitoneum associated with acute diverticulitis is not an indication for open or laparoscopic emergency surgery in hemodynamically stable patients. A 10-year experience with a nonoperative treatment. Surg Endosc 2012;26:2061-2071.

32 Gregersen R, et al: Treatment of patients with acute colonic diverticulitis complicated by abscess formation: a systematic review. Int J Surg 2016;35:201-208.

33 Hemming J, Floch M: Features and management of colonic diverticular disease. Curr Gastroenterol Rep 2010;12:399-407.

34 Lamb MN, Kaiser AM: Elective resection versus observation after nonoperative management of complicated diverticulitis with abscess: a systematic review and meta-analysis. Dis Colon Rectum 2014;57:1430-1440.

-35 Golfieri R, Cappelli A: Computed tomography-guided percutaneous abscess drainage in coloproctology: review of the literature. Tech Coloproctol 2007;11:197-208.

-36 Jaffe TA, Nelson RC: Image-guided percutaneous drainage: a review. Abdom Radiol (NY) 2016;41:629-636.
The Multidisciplinary Management of Acute Complicated Diverticulitis 
-37 Barkin JA, Barkin JS: Endoluminal diverticular abscess with endoscopic drainage: a new presentation and management of acute diverticulitis. Int J Colorectal Dis 2016;31:12431244.

38 Calzolari C, et al: Diverticular abscess successfully treated by endoscopic transluminal drainage. Clin Res Hepatol Gastroenterol 2014;38:e17-e18.

-39 Kosugi C, et al: Endoscopic transluminal abscess drainage for Hinchey II colonic diverticulitis. Int J Colorectal Dis 2012;27:12391240.

40 Ramesh J, et al: Comparison of outcomes between endoscopic ultrasound-guided transcolonic and transrectal drainage of abdominopelvic abscesses. J Gastroenterol Hepatol 2013;28:620-625

41 Tham JC, Smolarek SK, Coleman MG: Diverticulitis, pelvic and other intra-abdominal abscesses. Surgery (Oxford) 2017;35:456.

42 Gachabayov M, Essani R, Bergamaschi R: Laparoscopic approaches to complicated diverticulitis. Langenbecks Arch Surg, Epub ahead of print.

43 Jalouta T, et al: Diverticulitis recurrence after percutaneous abscess drainage. Int J Colorectal Dis 2017;32:1367-1373

$\checkmark 44$ Agresta F, et al: Laparoscopic approach to acute abdomen from the Consensus Development Conference of the Societa Italiana di Chirurgia Endoscopica e nuove tecnologie (SICE), Associazione Chirurghi Ospedalieri Italiani (ACOI), Societa Italiana di Chirurgia (SIC), Societa Italiana di Chirurgia d'Urgenza e del Trauma (SICUT), Societa Italiana di Chirurgia nell'Ospedalita Privata (SICOP), and the European Association for Endoscopic Surgery (EAES). Surg Endosc 2012;26:21342164.

45 O'Sullivan GC, et al: Laparoscopic management of generalized peritonitis due to perforated colonic diverticula. Am J Surg 1996;171: 432-434.

46 Rizk N, Champault G: Laparoscopic treatment in two operative stages of perforated sigmoid diverticulitis: 2 cases. Ann Chir 1996;50: 283.

47 Schultz JK, et al: Laparoscopic lavage vs primary resection for acute perforated diverticulitis: the SCANDIV Randomized Clinical Trial. JAMA 2015;314:1364-1375.

48 Thornell A, et al: Laparoscopic lavage for perforated diverticulitis with purulent peritonitis: a randomized trial. Ann Intern Med 2016 164:137-145.

49 Vennix S, et al: Laparoscopic peritoneal lavage or sigmoidectomy for perforated diverticulitis with purulent peritonitis: a multicentre, parallel-group, randomised, open-label trial. Lancet 2015;386:1269-1277.

50 Ceresoli M, et al: Laparoscopic lavage versus resection in perforated diverticulitis with purulent peritonitis: a meta-analysis of randomized controlled trials. World J Emerg Surg 2016;11:42.
51 Cirocchi R, et al: Laparoscopic lavage versus surgical resection for acute diverticulitis with generalised peritonitis: a systematic review and meta-analysis. Tech Coloproctol 2017;21: 93-110.

52 Shaikh FM, et al: Laparoscopic peritoneal lavage or surgical resection for acute perforated sigmoid diverticulitis: a systematic review and meta-analysis. Int J Surg 2017;38:130-137.

53 Angenete E, et al: Laparoscopic lavage is superior to colon resection for perforated purulent diverticulitis - a meta-analysis. Int J Colorectal Dis 2017;32:163-169.

54 Marshall JR, et al: Laparoscopic lavage in the management of Hinchey grade III diverticulitis: a systematic review. Ann Surg 2017;265: 670-676.

55 Galbraith N, et al: Laparoscopic lavage in the management of perforated diverticulitis: a contemporary meta-analysis. J Gastrointest Surg 2017;21:1491-1499.

56 Penna M, et al: Laparoscopic lavage versus primary resection for acute perforated diverticulitis: review and meta-analysis. Ann Surg 2018;267:252-258.

57 Biffl WL, Moore FA, Moore EE: What is the current role of laparoscopic lavage in perforated diverticulitis? J Trauma Acute Care Surg 2017;82:810-813.

58 Slim K, Le Roy B: Laparoscopic peritoneal lavage for perforated sigmoid diverticulitis - an example of surgical research failure. Colorectal Dis 2017;19:208.

59 Gehrman J, et al: Health economic analysis of laparoscopic lavage versus Hartmann's procedure for diverticulitis in the randomized DILALA trial. Br J Surg 2016;103:1539-1547.

60 Vennix S, et al: Cost analysis of laparoscopic lavage compared with sigmoid resection for perforated diverticulitis in the Ladies trial. $\mathrm{Br}$ J Surg 2017;104:62-68.

61 Di Saverio S, et al: The Ladies Trial: premature termination of the LOLA arm and increased adverse events incidence after laparoscopic lavage may be influenced by inter-hospital and inter-operator variability? Take-home messages from a center with laparoscopic colorectal expertise. Int J Surg 2016;36:118120.

62 Schultz JK, et al: One-year results of the SCANDIV randomized clinical trial of laparoscopic lavage versus primary resection for acute perforated diverticulitis. Br J Surg 2017; 104:1382-1392.

63 Vennix S, et al: Emergency laparoscopic sigmoidectomy for perforated diverticulitis with generalised peritonitis: a systematic review. Dig Surg 2016;33:1-7.

64 Vennix S, et al: Emergency laparoscopic sigmoidectomy for perforated diverticulitis with generalised peritonitis: a systematic review. Dig Surg 2016;33:1-7.
65 Vennix S, et al: Acute laparoscopic and open sigmoidectomy for perforated diverticulitis: a propensity score-matched cohort. Surg Endosc 2016;30:3889-3896.

66 Titu LV, et al: Emergency laparoscopic surgery for complicated diverticular disease. Colorectal Dis 2009;11:401-404.

67 Letarte F, et al: Laparoscopic versus open colonic resection for complicated diverticular disease in the emergency setting: a safe choice? A retrospective comparative cohort study. Am J Surg 2015;209:992-998.

68 Di Saverio S, et al: Pushing the envelope: laparoscopy and primary anastomosis are technically feasible in stable patients with Hinchey IV perforated acute diverticulitis and gross faeculent peritonitis. Surg Endosc 2016;30: 5656-5664

69 Di Saverio S: Emergency laparoscopy: a new emerging discipline for treating abdominal emergencies attempting to minimize costs and invasiveness and maximize outcomes and patients' comfort. J Trauma Acute Care Surg 2014;77:338-350.

70 Di Saverio S, et al: Improved outcomes when surgical postoperative complications are managed according to the principles of continuity of care and specificity of expertise. J Patient Saf 2017, Epub ahead of print.

71 Di Saverio S, et al: Surgeon accountability for patient safety in the Acute Care Surgery paradigm: a critical appraisal and need of having a focused knowledge of the patient and a specific subspecialty experience. Patient Saf Surg 2015;9:38.

72 Mandrioli M, Tugnoli G, Di Saverio S: Laparoscopic lavage versus primary resection for perforated diverticulitis. JAMA 2016;315: 1053.

73 Constantinides VA, et al: Primary resection with anastomosis vs. Hartmann's procedure in nonelective surgery for acute colonic diverticulitis: a systematic review. Dis Colon Rectum 2006;49:966-981.

74 Cirocchi R, et al: Treatment of Hinchey stage III-IV diverticulitis: a systematic review and meta-analysis. Int J Colorectal Dis 2013;28: 447-457.

75 Binda GA, et al: Primary anastomosis vs nonrestorative resection for perforated diverticulitis with peritonitis: a prematurely terminated randomized controlled trial. Colorectal Dis 2012;14:1403-1410.

76 Oberkofler CE, et al: A multicenter randomized clinical trial of primary anastomosis or Hartmann's procedure for perforated left colonic diverticulitis with purulent or fecal peritonitis. Ann Surg 2012;256:819-826; discussion 826-827.

77 Swank HA, et al: The ladies trial: laparoscopic peritoneal lavage or resection for purulent peritonitis and Hartmann's procedure or resection with primary anastomosis for purulent or faecal peritonitis in perforated diverticulitis (NTR2037). BMC Surg 2010;10:29. 